\title{
Prolactin and cortisol levels in women with endometriosis
}

A.P. Lima' ${ }^{1}$ M.D. Moura ${ }^{2}$ and A.A.M. Rosa e Silva ${ }^{1}$
${ }^{1}$ Departamento de Fisiologia, ${ }^{2}$ Departamento de Ginecologia e Obstetrícia, Faculdade de Medicina de Ribeirão Preto, Universidade de São Paulo, Ribeirão Preto, SP, Brasil

\section{Correspondence}

A.P. Lima

R. Sirley Pereira Arantes, 73/204

38408-735 Uberlândia, MG

Brasil

E-mail: apljh@hotmail.com

Research supported by FAPESP.

Received May 31, 2005

Accepted May 23, 2006

\begin{abstract}
Endometriosis is a progressive estrogen-dependent disease affecting women during their reproductive years. The objective of the present study was to investigate whether endometriosis is associated with stress parameters. We determined cortisol and prolactin levels in serum, peritoneal and follicular fluid from infertile women with endometriosis and fertile women without the disease. The extent of the disease was staged according to the revised American Fertility Society classification (1997). Serum and peritoneal fluid were collected from 49 women aged 19 to 39 years undergoing laparoscopy. Eighteen women had stage I-II endometriosis and 10 had stage III-IV. Controls were 21 women undergoing laparoscopy for tubal sterilization. Follicular fluid was obtained from 39 women aged 25-39 years undergoing in vitro fertilization (21 infertile women with endometriosis and 18 infertile women without endometriosis). Serum prolactin levels were significantly higher in infertile women with stage III-IV endometriosis $(28.9 \pm 2.1 \mathrm{ng} / \mathrm{mL})$ than in healthy controls $(13.2 \pm 2.1 \mathrm{ng} / \mathrm{mL})$. Serum cortisol levels were significantly higher in infertile women with stage III-IV endometriosis $(20.1 \pm 1.3 \mathrm{ng} / \mathrm{mL})$ than in controls $(10.5 \pm 1.4 \mathrm{ng} / \mathrm{mL})$. Cortisol and prolactin levels in follicular fluid and peritoneal fluid did not differ significantly between groups. The high levels of cortisol and prolactin in the serum from women with endometriosis might contribute to the subfertility frequently associated with the disease. Moreover, since higher levels of cortisol and prolactin are often associated with stress, it is probable that stress might contribute to the development of endometriosis and its progression to advanced stages of the disease.
\end{abstract}

Key words - Endometriosis - Stress - Infertility

- Prolactin

- Cortisol

\section{Introduction}

Endometriosis is a clinically insidious disease, being one of the most common benign diseases affecting women of reproductive age. It is characterized by the presence and growth of ectopic endometrial tissue outside the endometrial cavity. This complex disease is a common gynecologic problem frequently associated with infertility and pelvic pain (1). Endometriosis, endometriosis-associated reproductive failure and idiopathic infertility are still among the most difficult problems facing the gynecologist. 
However, the pathophysiology and pathogenesis of endometriosis are unknown. A significant number of women who complain of dysmenorrhea and pelvic pain have endometriosis, and more than $50 \%$ of women with unexplained infertility are diagnosed with endometriosis by laparoscopy. The incidence of endometriosis seems to be increasing (2-4).

In recent years, considerable evidence has pointed to immunological changes in the peritoneal cavity of women with endometriosis. Several studies indicate that immunological mechanisms are involved in the pathophysiology of endometriosis and endometriosis-associated reproductive failure (1-7). The main conclusions of these studies indicate an increased number of activated macrophages and their immune mediators, which may substantially interfere with reproduction at various levels, including gamete function, fertilization, embryo development, and embryo implantation. Furthermore, women with endometriosis have reduced cellular immunity and more specifically a decreased natural killer (NK) activity in peripheral blood and in peritoneal fluid (8-10). It is also well known that parameters associated with stress can significantly alter several immunological parameters, including the number of cells as well as their function (for a review, see Ref. 11). Stress, whatever physical or emotional, activates neurons that secrete corticotropin-releasing hormone, which results in higher plasma cortisol levels. Prolactin is also released in response to stressor stimuli, although its exact role in the response to stress is not known (11). Several lines of evidence suggest that stress, which is characterized by increased levels of cortisol, inhibits NK cell activity. In fact, these are the cells most susceptible to the effects of cortisol, and their activity is considered to be a reliable indicator of the cell immunity suppression caused by stress (11).

Based on these lines of evidence, we were interested in determining whether the presence of endometriosis is associated with these stress parameters. Therefore, the present study was undertaken to measure cortisol and prolactin levels in serum, peritoneal fluid and follicular fluid from patients with endometriosis and without the disease.

\section{Material and Methods}

Serum and peritoneal fluid were collected from 49 women aged 19 to 39 years undergoing laparoscopy, which was indicated for the evaluation of infertility, pelvic pain, or for tubal ligation.

Endometriosis was diagnosed laparoscopically. The extent of the disease was staged according to the revised American Fertility Society classification (12). Peritoneal fluid was collected from infertile women with endometriosis $(\mathrm{N}=28)$ and fertile women without endometriosis ( $\mathrm{N}=21)$. Eighteen women had stage I-II endometriosis and 10 had stages III-IV. Controls were 21 women undergoing laparoscopy for tubal sterilization. None of these women had received any hormonal treatment for three months prior to diagnostic laparoscopy, which was performed during the secretory phase. Only patients with regular menstrual cycles were used in this study.

Follicular fluid was obtained from 39 women aged 25-39 years undergoing in vitro fertilization-embryo transfer at the Department of Obstetrics and Gynecology, School of Medicine of Ribeirão Preto (University of São Paulo).

The patients were divided into two groups: 21 infertile women with endometriosis and 18 infertile women without endometriosis. Endometriosis was diagnosed according to the revised American Fertility Society classification during previous diagnostic laparoscopy. All control patients (male factor infertility only) underwent diagnostic laparoscopy as part of their infertility workup and were found to be free of endometriosis implants by visual assessment. 
The study was approved by the Ethics Committee of the Faculty of Medicine of Ribeirão Preto, University of São Paulo and all patients gave written informed consent to participate.

\section{Peritoneal fluid collection}

Samples of peritoneal fluid were obtained from Douglas' pouch as soon as the pelvic cavity was visualized during laparoscopy for tubal ligation or evaluation of infertility. All samples were centrifuged at $400 \mathrm{~g}$ for 15 $\min$ at $4^{\circ} \mathrm{C}$ and supernatant fluids were stored in sterile tubes at $-20^{\circ} \mathrm{C}$.

\section{Follicular fluid collection}

Follicular fluid, only of dominant follicles, was used for this study. This permitted the collection of more homogeneous samples without blood contamination. Oocyte retrieval was performed $34 \mathrm{~h}$ after the injection of hCG. After removal of the cumulus-oocytes complexes, samples of follicular fluid were centrifuged at $600 \mathrm{~g}$ at $4^{\circ} \mathrm{C}$ for $20 \mathrm{~min}$. The cell-free supernatants were then stored in sterile tubes at $-80^{\circ} \mathrm{C}$.

\section{Blood sampling}

Blood samples were taken from all patients undergoing laparoscopy immediately before the induction of anesthesia, for the collection of serum. Therefore, no anticoagulant was used. The supernatant formed after blood coagulation (serum) was stored in sterile tubes at $-20^{\circ} \mathrm{C}$ until assayed.

\section{Measurements of cortisol and prolactin}

Cortisol and prolactin concentrations in serum, peritoneal fluid and follicular fluid were determined by chemoluminescence using commercial kits from Diagnostics Products Corporation (DPC, Immulite System, Los Angeles, CA, USA).
For cortisol, the interassay coefficient of variation was $7.8,9.6$, and $11.2 \%$ and the intra-assay coefficient of variation was 6.4 , 9.3 , and $10.1 \%$ for serum, peritoneal fluid and follicular fluid, respectively. For prolactin, the interassay coefficient of variation was $8.8,7.6$, and $9.4 \%$ and the intra-assay coefficient of variation was $11.3,10.3$, and $8.1 \%$ for serum, peritoneal fluid and follicular fluid, respectively.

\section{Statistical analysis}

For the collection of blood and peritoneal fluid, the estimate of sample size was based on a total of 81 patients distributed as follows: women with stage I-II endometriosis $(\mathrm{N}=29)$, women with stage III-IV endometriosis $(\mathrm{N}=18)$ and fertile women without endometriosis $(\mathrm{N}=34)$. However, some of these patients were not included in this study because of minimum differences in their cycles.

In order to determine how many members of the population should be selected to ensure that the population is properly represented, we used the following formula (for a review, see Ref. 13):

$$
\eta=\left[\frac{z_{\mathrm{a} / 2} \sigma}{\mathrm{E}}\right]^{2}
$$

where $\mathrm{z}_{\mathrm{a} / 2}$ represents the confidence level. The degree of confidence used was $95 \%$. In the table of the standard normal (z) distribution, a 95\% degree of confidence corresponds to the value of 1.96; $\sigma$ is the population standard deviation (SD), $\eta$ is the sample size, and $\mathrm{E}$ represents the margin of error, i.e., the maximum difference between the observed sample mean and the true value of the population mean.

Therefore, as described in Material and Methods, for the collection of blood and peritoneal fluid, a total of 49 patients were selected for this study. These patients were distributed as follows: 21 fertile women without endometriosis, 18 infertile women with 
stage I-II endometriosis and 10 infertile women with stage III-IV endometriosis. For the collection of follicular fluid a total of 39 women were selected and divided into two groups: 21 infertile women with endometriosis and 18 infertile women without endometriosis (Tables 1 and 2).

The margin of error for the number of patients included in each group was calculated using the formula described above. The degree of confidence used was $95 \%$.

Therefore, for the number of patients included in the present study, the mean margin of error was $4.5 \%$, with a degree of confidence of $95 \%$. With these statistical values, we considered the number of patients included in each group to be appropriate for the parameters analyzed in the present study.

The cortisol/prolactin concentrations in the serum and peritoneal fluid from the different subgroups were compared by the Kruskal-Wallis test, followed by the Dunn test. The cortisol/prolactin concentrations in the follicular fluid from the endometriosis group were compared with control by the two-tailed Student $t$-test. Statistical significance was defined as $\mathrm{P}<0.05$. Results are reported as mean $\pm \mathrm{SD}$.

\section{Results}

\section{Prolactin concentrations}

Prolactin concentrations in women with and without endometriosis are presented in Tables 3 and 4. As shown in Table 3, serum prolactin levels were significantly higher in infertile women with stage III-IV endometriosis $(28.9 \pm 2.1 \mathrm{ng} / \mathrm{mL})$ than in fertile women without endometriosis $(13.2 \pm 2.1 \mathrm{ng} / \mathrm{mL})$. Infertile women with stage I-II endometriosis presented values $(23.4 \pm 3.7 \mathrm{ng} / \mathrm{mL})$ similar to those of infertile women with stage IIIIV endometriosis. Prolactin levels in peritoneal fluid did not differ significantly between different stages of endometriosis (13.5 $\pm 1.34 \mathrm{ng} / \mathrm{mL}$ for stages I-II; $14.1 \pm 1.56 \mathrm{ng} /$ $\mathrm{mL}$ for stages III-IV) compared to healthy controls $(11.4 \pm 1.3 \mathrm{ng} / \mathrm{mL})$. Table 4 shows that follicular fluid prolactin levels did not differ significantly between infertile women with endometriosis $(46.5 \pm 5.2 \mathrm{ng} / \mathrm{mL})$ and infertile women without endometriosis (44.5 $\pm 5.2 \mathrm{ng} / \mathrm{mL}$ )

\section{Cortisol concentrations}

Cortisol concentrations in women with and without endometriosis are presented in Tables 3 and 4. As shown in Table 3, serum cortisol levels were significantly higher in infertile women with stage III-IV endometriosis $(20.1 \pm 1.3 \mathrm{ng} / \mathrm{mL})$ than in fertile women without endometriosis $(10.5 \pm 1.4 \mathrm{ng} / \mathrm{mL})$. Infertile women with stage I-II endometriosis presented intermediate values $(14.8 \pm 1.2$ $\mathrm{ng} / \mathrm{mL}$ ). Cortisol levels in peritoneal fluid did not differ significantly between different stages of endometriosis $(4.8 \pm 0.21 \mathrm{ng} / \mathrm{mL}$ for stages I-II and $4.4 \pm 0.11 \mathrm{ng} / \mathrm{mL}$ for stages III-IV) compared to healthy controls $(4.4 \pm 0.13 \mathrm{ng} / \mathrm{mL})$. Table 4 shows that

\begin{tabular}{|c|c|c|c|}
\hline Parameters analyzed & $\begin{array}{l}\text { Fertile women } \\
\text { without endometriosis } \\
\qquad(\mathrm{N}=21)\end{array}$ & $\begin{array}{c}\text { Infertile women } \\
\text { with stage I-II } \\
\text { endometriosis }(\mathrm{N}=18)\end{array}$ & $\begin{array}{c}\text { Infertile women } \\
\text { with stage III-IV } \\
\text { endometriosis }(N=10)\end{array}$ \\
\hline Cortisol in serum (ng/mL) & $5.7 \%$ & $3.7 \%$ & $3.9 \%$ \\
\hline Cortisol in peritoneal fluid (ng/mL) & $3.9 \%$ & $2.1 \%$ & $1.6 \%$ \\
\hline Prolactin in serum (ng/mL) & $6.7 \%$ & $7.2 \%$ & $4.5 \%$ \\
\hline Prolactin in peritoneal fluid ( $\mathrm{ng} / \mathrm{mL}$ ) & $5.0 \%$ & $4.2 \%$ & $6.8 \%$ \\
\hline
\end{tabular}


follicular fluid cortisol levels did not differ significantly between infertile patients with endometriosis $(7.9 \pm 0.63 \mathrm{ng} / \mathrm{mL})$ and without endometriosis $(8.2 \pm 0.79 \mathrm{ng} / \mathrm{mL})$.

\section{Discussion}

Endometriosis is a heterogeneous disease, strongly associated with hormonal and immunological alterations. Among the hormonal alterations associated with the endometriosis, hyperprolactinemia is one of the conditions most frequently mentioned in the literature. Many researchers have investigated the relation between serum prolactin levels and infertility in patients with endometriosis, but the results are controversial. Some investigators have suggested that relative hyperprolactinemia may be responsible for the infertility associated with endometriosis (14-17), whereas others did not detect a significant increase in prolactin levels in women with endometriosis, thus ruling out hyperprolactinemia as a cause of infertility (18-20).

Gregoriou et al. (15) observed a direct correlation between prolactin secretion and disease stage, with serum prolactin concentration progressively increasing from stage I to stage IV, a pattern also observed in the present study, in which infertile women with stage III-IV endometriosis presented significantly higher prolactin concentrations compared to healthy women. We did not detect a significant difference in prolactin concentrations in peritoneal fluid or follicular fluid, between women with and without endometriosis. Haney et al. (21) also did not observe a variation of prolactin concentration in the peritoneal fluid of women with endometriosis, concluding that the ectopic endometrium of women with endometriosis does not secrete prolactin in amounts sufficient to elevate peritoneal fluid concentrations. On the other hand, Hao et al. (22) observed not only that the ectopic implants of endometriosis secrete prolactin in a sig- nificant way, but also that there is a significant positive association between prolactin secretion by ectopic endometrial cells and the scoring of endometriosis.

Although there is controversy in the literature, we believe that higher levels of serum prolactin might be associated with endometriosis and its progression, as shown by

Table 2. Margin of error based on the number of patients included in each group for the collection of follicular fluid.

\begin{tabular}{lcc}
\hline Parameters analyzed & $\begin{array}{c}\text { Infertile women with } \\
\text { endometriosis }(\mathrm{N}=21)\end{array}$ & $\begin{array}{c}\text { Infertile women without } \\
\text { endometriosis }(\mathrm{N}=18)\end{array}$ \\
\hline Cortisol $(\mathrm{ng} / \mathrm{mL})$ & $2.4 \%$ & $4.4 \%$ \\
Prolactin $(\mathrm{ng} / \mathrm{mL})$ & $4.98 \%$ & $5.2 \%$ \\
\hline
\end{tabular}

Table 3. Prolactin and cortisol concentrations in serum and peritoneal fluid of fertile women without endometriosis, of infertile women with stage I-II endometriosis and stage III-IV endometriosis.

\begin{tabular}{lccc}
\hline Parameters analyzed & $\begin{array}{c}\text { Fertile women } \\
\text { without } \\
\text { endometriosis } \\
(\mathrm{N}=21)\end{array}$ & $\begin{array}{c}\text { Infertile women } \\
\text { with stage I-II } \\
\text { endometriosis } \\
(\mathrm{N}=18)\end{array}$ & $\begin{array}{c}\text { Infertile women } \\
\text { with stage III-IV } \\
\text { endometriosis } \\
(\mathrm{N}=10)\end{array}$ \\
\hline $\begin{array}{c}\text { Prolactin in serum }(\mathrm{ng} / \mathrm{mL}) \\
\text { Prolactin in peritoneal fluid } \\
(\mathrm{ng} / \mathrm{mL})\end{array}$ & $13.2 \pm 2.1^{\mathrm{a}}$ & $23.4 \pm 3.7^{\mathrm{b}}$ & $28.9 \pm 2.1^{\mathrm{b}}$ \\
$\begin{array}{l}\text { Cortisol in serum }(\mathrm{ng} / \mathrm{mL}) \\
\text { Cortisol in peritoneal fluid } \\
(\mathrm{ng} / \mathrm{mL})\end{array}$ & $10.5 \pm 1.4^{\mathrm{a}}$ & $14.8 \pm 1.2^{\mathrm{a}}$ & $20.1 \pm 1.3^{\mathrm{b}}$ \\
\hline
\end{tabular}

Data are reported as mean \pm SD. Different letters indicate statistically significant differences between means. Absence of letters indicates that there is no significant difference between groups $(P<0.05$, Kruskal-Wallis test, followed by Dunn test).

Table 4. Cortisol and prolactin concentrations in follicular fluid of infertile women without endometriosis and infertile women with endometriosis.

\begin{tabular}{lcc}
\hline Parameters analyzed & $\begin{array}{c}\text { Infertile women } \\
\text { without } \\
\text { endometriosis } \\
(\mathrm{N}=18)\end{array}$ & $\begin{array}{c}\text { Infertile women } \\
\text { with } \\
\text { endometriosis } \\
(\mathrm{N}=21)\end{array}$ \\
\hline Cortisol in follicular fluid $(\mathrm{ng} / \mathrm{mL})$ & $8.2 \pm 0.79$ & $7.9 \pm 0.63$ \\
Prolactin in follicular fluid $(\mathrm{ng} / \mathrm{mL})$ & $44.5 \pm 5.2$ & $46.5 \pm 5.2$
\end{tabular}

Data are reported as mean $\pm S D$. There was no significant difference between groups ( $\mathrm{P}>0.05$, Student $t$-test). 
the present results and in agreement with most of the evidence reported in the literature (14-17).

The present study also demonstrated that the serum cortisol concentrations of infertile women with stage III/IV endometriosis were significantly elevated compared to fertile women without endometriosis. In peritoneal and follicular fluid, we failed to detect a significant variation of cortisol concentration between groups. However, Smith et al. (23) reported that cortisol levels were reduced in the periovulatory follicle of infertile women with minimal-mild endometriosis, compared with controls (women with tubal infective damage). Their findings provide further evidence of follicular dysfunction contributing to the subfertility associated with minimal-mild endometriosis. The role of glucocorticoids in human oocyte maturation is not fully understood, but the presence of active glucocorticoid (cortisol) may be important for oocyte maturation and embryo implantation. Conception and embryo transfer have been associated with higher intrafollicular cortisol concentrations (24).

The divergence between our results and those obtained by Smith et al. (23) leads us to ask whether there might be different physiological subtypes of endometriosis that produce different hormone profiles. We believe that further studies should be conducted in order to clarify the specific conditions that might lead or not to an alteration of cortisol concentrations in follicles of women with endometriosis.

The higher levels of serum cortisol in women with endometriosis might be associated with either physical or emotional stress, which may contribute to the development of the disease. The pathogenesis of endometriosis remains obscure. In the last years, considerable evidence has pointed to immune changes in the peritoneal cavity that may contribute to the development of endometriosis. There is substantial evidence that immunological factors play a role in the pathogenesis of en- dometriosis and endometriosis-associated reproductive failure. Several lines of evidence indicate stress-related hormones as immunosuppressive agents, which present a range of effects on the immune system (11).

Stress activates neurons that secrete corticotropin-releasing hormone, which results in higher plasma cortisol levels. Prolactin is also released in response to stressor stimuli, although its exact role in the response to the stress is not known (11). In the present study, we observed an increase of both cortisol and prolactin in infertile women with endometriosis.

It is well known that women with endometriosis have a decreased cellular immunity and a decreased NK activity in peripheral blood and in peritoneal fluid (8-10). Stress, which is followed by increased cortisol levels, inhibits NK cell activity. In fact, these cells appear to be the most susceptible to the suppressive effects of stress and NK cell activity is considered to be a reliable indicator of cell immunity suppression caused by stress (11). Thus, the increase of prolactin and cortisol secretion and the simultaneous reduction of NK cell activity in women with endometriosis are strong clues of a probable association between endometriosis and stress.

Numerous theories have been proposed for the origin of endometriosis. Cellular and biochemical constituents of peritoneal fluid have been reported to play an important role in the pathogenesis of endometriosis (for a review, see Refs. 2 and 25).

It has been postulated that viable endometrial cells reaching the peritoneal cavity by retrograde menstruation could implant more easily in women with a defective immunological defense mechanism (26). The lower activity of NK cells and T lymphocytes in the peritoneal cavity might be the key factor in the deficient elimination of ectopic endometrium (27).

The peripheral increase of cortisol, which inhibits both NK cell activity and T lymphocytes, could favor the development of en- 
dometriosis in women predisposed to developing the disease. Thus, women submitted to higher levels of stress, might be more vulnerable to developing endometriosis.

Whether the serum cortisol increase in women with endometriosis is one of the multiple causes of endometriosis or just a consequence of the disease is a complex question which requires further study. However, the increase of cortisol secretion in infertile women with endometriosis broadens the perspectives for the understanding of the pathogenesis of endometriosis and of the infertility often associated with the disease.

\section{Acknowledgments}

We would like to thank Maria Albina Vercezi Bortolieiro for technical assistance.

\section{References}

1. Mahmood TA, Templeton A. Pathophysiology of mild endometriosis: review of literature. Hum Reprod 1990; 5: 765-784.

2. Christiman GM, Halme JK. Pathophysiology of endometriosis-associated symptoms. Fertil Steril 1992; 3: 551-564.

3. Hill JA. Immunology and endometriosis. Fertil Steril 1992; 58: 262264.

4. Thomas EJ, Prentice A. The aetiology and pathogenesis of endometriosis. Reprod Med Rev 1992; 1: 21-36.

5. Ramey JW, Archer DF. Peritoneal fluid: its relevance to the development of endometriosis. Fertil Steril 1993; 60: 1-14.

6. D'Hooghe TM, Hill JA. Immunobiology of endometriosis. In: Bronson RA, Alexander NJ, Anderson D, Branch DW, Kutteh WH (Editors), Reproductive immunology. Cambridge: Blackwell Science; 1996. $\mathrm{p}$ 322-356.

7. Vinatier D, Dufour P, Oosterlynck D. Immunological aspects of endometriosis. Hum Reprod Update 1996; 2: 371-384.

8. Oosterlynck DJ, Cornille FJ, Waer M, Vandeputte M, Koninckx PR. Women with endometriosis show a defect in natural killer activity resulting in a decreased cytotoxity to autologous endometrium. Fertil Steril 1991; 56: 45-51.

9. Oosterlynck DJ, Meuleman C, Waer M, Vandeputte M, Koninckx PR. The natural killer activity of peritoneal fluid lymphocytes is decreased in women with endometriosis. Fertil Steril 1992; 58: 290295.

10. Wu MY, Ho HN, Chen SU, Chao KH, Chen CD, Yang YS. Increase in the production of interleukin-6, interleukin-10, and interleukin-12 by lipopolysaccharide-stimulated peritoneal macrophages from women with endometriosis. Am J Reprod Immunol 1999; 41: 106-111.

11. Chrousos GP, Elenkov IJ. Interactions of the endocrine and immune systems. In: DeGroot LJ, Jameson JL (Editors), Endocrinology. New York: Academic Press; 2000. p 571-586.

12. ASRM. Revised American Society for Reproductive Medicine classification of endometriosis: 1996. Fertil Steril 1997; 67: 817-821.

13. Bolfarine $\mathrm{H}$, Bussab WO. Elementos de amostragem, ABE - Projeto Fisher. Florida: Edgard Blücher; 2005

14. Machida T, Taga M, Minaguchi H. Prolactin secretion in endometriotic patients. Eur J Obstet Gynecol Reprod Biol 1997; 72: 89-92.

15. Gregoriou G, Bakas P, Vitoratos N, Papadias K, Goumas K, Chryssicopoulos A, et al. Evaluation of serum prolactin levels in patients with endometriosis and infertility. Gynecol Obstet Invest 1999; 48: 48-51.
16. Cunha-Filho JS, Gross JL, Lemos NA, Brandelli A, Castillos M, Passos EP. Hyperprolactinemia and luteal insufficiency in infertile patients with mild and minimal endometriosis. Horm Metab Res 2001; 33: 216-220.

17. Cunha-Filho JS, Gross JL, Lemos NA, Dias EC, Vettori D, Souza $\mathrm{CA}$, et al. Prolactin and growth hormone secretion after thyrotrophinreleasing hormone infusion and dopaminergic (DA2) blockade in infertile patients with minimal/mild endometriosis. Hum Reprod 2002; 17: 960-965.

18. Arumugam K. Serum prolactin levels in infertile patients with endometriosis. Malays J Pathol 1991; 13: 43-45.

19. Panidis D, Vavilis D, Rousso D, Panidou E, Kalogeropoulos A. Provocative tests of prolactin before, during and after long-term danazol treatment in patients with endometriosis. Gynecol Endocrinol 1992; 6: 19-24.

20. Matalliotakis I, Panidis D, Vlassis G, Vavilis D, Neonaki M, Koumantakis E. PRL, TSH and their response to the $\mathrm{TRH}$ test in patients with endometriosis before, during, and after treatment with danazol. Gynecol Obstet Invest 1996; 42: 183-186.

21. Haney AF, Handwerger S, Weinberg JB. Peritoneal fluid prolactin in infertile women with endometriosis: lack of evidence of secretory activity by endometrial implants. Fertil Steril 1984; 42: 935-938.

22. Hao M, Shi Y, Zhou C. In vitro study of prolactin secretion by ectopic endometrial stromal cells. Zhonghua Fu Chan Ke Za Zhi 2000; 35: 527-529.

23. Smith MP, Keay SD, Margo FC, Harlow CR, Wood PJ, Cahill DJ, et al. Total cortisol levels are reduced in the periovulatory follicle of infertile women with minimal-mild endometriosis. Am J Reprod Immunol 2002; 47: 52-56.

24. Keay SD, Harlow CR, Wood PJ, Jenkins JM, Cahill DJ. Higher cortisol:cortisone ratios in the preovulatory follicle of completely unstimulated IVF cycles indicate oocytes with increased pregnancy potential. Hum Reprod 2002; 17: 2410-2414.

25. Koninckx PR, Kennedy SH, Barlow DH. Pathogenesis of endometriosis: the role of peritoneal fluid. Gynecol Obstet Invest 1999; 47 (Suppl 1): 23-33.

26. Dmowski WP, Steele RW, Baker GF. Deficient cellular immunity in endometriosis. Am J Obstet Gynecol 1981; 141: 377-383.

27. Ho HN, Wu MY, Chen SU, Chao KH, Chen CD, Yang YS. Total antioxidant status and nitric oxide do not increase in peritoneal fluids from women with endometriosis. Hum Reprod 1997; 12: 2810-2815. 